lecturer in mathematics at Cambridge; he was awarded the Rayleigh Prize in 1949. Dr. Domb is distinguished for his work on the solid state, particularly in relation to the statistical mechanics of co-operative phenomena.

\section{Higher Technological Education in Great Britain}

IN reply to a question in the House of Commons on July 20, the Chancellor of the Exchequer stated that the plans announced for development of higher technological education in Leeds and Birmingham apply only to work in the universities, and do not include the upgrading of technical colleges. A considerable constructional programme is being carried out with the assistance of non-recurrent grants to improve and enlarge the accommodation at universities for technological work, and the cost of the new buildings for these studies which have been started in 1953 and 1954 is estimated at about $£ 2 \cdot 7$ million, most of which will be met by grant.

A memorandum on higher technological education drafted by the Parliamentary and Scientific Committee before the Chancellor of the Exchequer made his first statement on July 13 states that there is a considerable unsatisfied demand for scientists, engineers and other technologists in British industry, particularly for metallurgists and chemical engineers and those able to take posts in management or production. This demand is expected to grow, and the Committee considers that further government action to improve facilities for higher technological educa. tion is urgently needed. So far as the universities are concerned, the Committee recommends an increase in the proportion of students of science and technology within the present limits of student numbers, and expansion of postgraduate facilities particularly in fields of study of importance to local industrial interests. It also recommends extending the conditions of admission to postgraduate work and an incrcase in the number of bursaries from government and industrial sources. As regards colleges of tech. nology, the Committee recommends that a limited number, ultimately twenty, of colleges of technology should be given charters as royal colleges of technology, with the maximum academic autonomy, and financial independence on a quinquennial basis such as the universities enjoy, subject to a special grants committee closely co-operating with the University Grants Committee. Both the regional advisory councils and the local authorities of the region would be represented on the governing bodies as well as scientific, technological, industrial and commercial interests. The colleges, which would includo a reasonable infusion of the humanities in the courses, would be entitled to award the degree of bachelor of technology, and this should be of sufficient standard to qualify its holder for postgraduate work in a university. The memorandum refers also to the shortage of science teachers and the need for intensive and longterm efforts by industry and the profossional institutions to break down the prejudice of those leaving school against careers in applied science, as well as the need for greater co-operation between industry and the universities and technical colleges in the interchange of staff and in other ways.

\section{Financial Estimates tor the Department of Scientific} and Industrial Research

Is reply to questions in the House of Commons on July 20 regarding the Department of Scientific and Industrial Rescarch, Mr. J. R. Bevins, Parliamentary
Secretary to the Ministry of Works as representing the Lord President of the Council, said that the estimates for the present financial year provide for an increase in gross expenditure of $£ 71,440$ and an increase of staff of 197 compared with last year. It is expected that about fifty of the additional posts will be filled by industrial staff, and most of the others will be in the scientific officer, experimental officer and assistant (scientific) classes. Provision for a further two hundred posts, of which about fifty will be for industrial staff, is planned for each of the four financial years $1955-56$ to $1958-59$. The present establishment at the Chemical Research Laboratory is 193 compared with 184 in July 1953, and consists of 159 non-industrial and 34 industrial staff. Nine of the present twelve vacancies are expected to be filled in the near future. The major works included in the Department's building programme for 1954-55 are the Hydraulics Research Station $(£ 159,800)$, Mechanical Engineering Research Laboratory (£254,600), National Physical Laboratory (£111,700), Radio Research Station $(£ 92,500)$ and the Water Pollution Research Laboratory $(\mathfrak{1 1 5}, 000)$. The Water Pollution Research Laboratory will be completed and occupied this year, and the work at the Hydraulies Research Station should also be nearing completion. Work on the now Radio Research Station began this year and is expected to be completed in 1955-56. The provision for the National Physical Laboratory is principally for the commencement of construction of a new ship tank (for research and testing on the form of ships' hulls and propellers), which is expected to take some four to five years to complete.

\section{Heavy-Water Reactor (Dimple) at Harwell}

THE United Kingdom Atomic Energy Authority has announced that a heavy-water reactor (or atomic pile) which has been built at the Atomic Energy Research Establishment, Harwell, is now in operation. 'Dimple' is a low-powered thermal neutron research reactor. The heavy-water moderator is contained in a tank which is surrounded by a graphite neutron reflector. Outside this is a concrete radiation shield. The reactor fuel is submerged in the heavy water. Both the type of fuel and its arrangement in the tank can be changed quickly so that what is, in effect, a different design of reactor can be built up in a matter of a few days. The reactor will only be operated at very low power so that its structure does not become sufficiently radioactive to prevent the necessary handling. The behaviour of the wide variety of design can, therefore, be investigated experimentally in a relatively short time. The versatility of Dimple will make it an extremely valuable tool in the design of future power-producing reactors and for measuring essential constants in reactor physics. One of the first functions of Dimple will be to carry out experimental work for $E .443$, the new and more powerful heavy-water reactor which is now being built at Harwell to provide the high neutron flux essential for some research purposes.

\section{European Atomic Energy Society}

Representatives from eight European Atomic Energy Commissions have agreed to establish a European Atomic Energy Society (Société Européenne d'Énergie Atomique). The eight nations represented are: Belgium, France, Italy, The Netherlands, Norway, Sweden, Switzerland and the United Kingdom. The chief aim of the new Society is to promoto co-operation in nuclear energy research and engineer- 